\title{
Conflitos no uso do solo e sua relação com a conservação ambiental: um estudo de caso
}

\section{Camila Aparecida de Lima1 e Flávia Peres Nunes²}

${ }^{1}$ Pontifícia Universidade Católica de Minas Gerais (PUC Minas). Curso de MBA em Gestão da Qualidade Integrada ao Meio Ambiente. Av. Dom José Gaspar, 500. Coração Eucarístico. Belo Horizonte-MG, Brasil (CEP 30535-901). E-mail: camiladelimabio@gmail.com.

${ }^{2}$ Pontifícia Universidade Católica de Minas Gerais (PUC Minas). Pós-Graduação lato sensu. Instituto de Educação Continuada (IEC PUC Minas). Av. Dom José Gaspar, 500. Coração Eucarístico. Belo Horizonte-MG, Brasil (CEP 30535-901).

Resumo. As intervenções humanas alteram a paisagem natural. Este estudo de caso de uma propriedade rural em uma área de Mata Atlântica em Minas Gerais, Brasil, visa a evidenciar como os conflitos no uso do solo e o uso inadequado dos recursos naturais, não atentando para a legislação ambiental, interferem na conservação. 0 estudo justifica-se pela importância e necessidade de aliar o desenvolvimento socioeconômico à conservação ambiental. Para tal foi levantada a Legislação aplicável à região e os dados geoespaciais analisados na plataforma IDE-Sisema. Como resultado, foram propostas medidas de recuperação de mata nativa e curso d'água para fins de uso sustentável da propriedade e adequação a legislação ambiental.

Palavras-chave: Conflitos no uso do solo; Conservação; Legislação ambiental; IDE-Sisema.

Abstract. Conflicts in land use and its relationship with the environmental conservation: $\boldsymbol{A}$ case study. The human intervention changes the natural landscape. This study from a rural property in an Atlantic Forest area in Minas Gerais, Brazil, aims to highlight how the conflicts in land use and the misuse of natural resources, not paying attention to the environmental legislation, interfere in the conservation. The study is justified by the importance and necessity of combining economic and social development to environmental conservation. For such legislation was raised to the region and the geospatial data analyzed in IDESisema platform. As a result, recovery measures were proposed of native Forest and water course for the purpose of sustainable use of the property and compliance with environmental legislation.

Keywords: Conflicts in land use; Conservation; Environmental legislation; IDE-Sisema.

ISSN 2359-1412/RBGAS-2020-0021/2020/7/16/16/691

Rev. Bras. Gest. Amb. Sustent.

http://revista.ecogestaobrasil.net 


\section{Introdução}

As intervenções humanas no meio ambiente alteram a paisagem natural. A Legislação Ambiental regulamenta as atividades antrópicas visando, em linhas gerais, a aliar o desenvolvimento econômico à conservação ambiental.

0 art. 225, da Constituição Federal de 1988 afirma que:

Todos têm direito ao meio ambiente ecologicamente equilibrado, bem de uso comum do povo e essencial à sadia qualidade de vida, impondo-se ao Poder Público e à coletividade o dever de defendê-lo e preservá-lo para as presentes e futuras gerações (Brasil, 1988).

A Constituição Federal de 1988 recepcionou a Política Nacional do Meio Ambiente, Lei no 6.939/1981, que objetiva preservar, melhorar e recuperar a qualidade ambiental propícia a vida, assegurando o desenvolvimento socioeconômico, interesses de segurança nacional e a proteção da dignidade da vida humana atendendo, entre outros, os princípios da manutenção do equilíbrio ecológico, racionalização do uso do solo, subsolo, água e ar e recuperação de áreas degradadas (Brasil, 1981).

A expressão "uso do solo" corresponde à maneira como o homem utiliza o solo (Feltran-Filho, 1989), e o uso e manejo inadequados do solo aliados a falta de ações conservacionistas resultam em problemas ambientais, trazendo prejuízos significativos para o solo, biodiversidade, água e para a população rural. O levantamento do uso do solo como parte de um diagnóstico ambiental é o início para planejamento conservacionista como estratégia para a reversão desse quadro (Santos, 2009; Vaeza et al., 2010).

Planejar as atividades no meio rural levando em consideração a capacidade do uso da terra mostra-se de extrema importância quando se objetiva o uso sustentável dos recursos naturais e a conservação do meio ambiente (Galatti Filho, 2006).

A legislação ambiental procura atender as necessidades de um país que apresenta um crescimento urbano e expansão de fronteiras agrícolas desordenados (Silva et al., 2011). Ela diferencia preservar e conservar: preservar consiste na proibição da exploração econômica dos recursos naturais, enquanto conservar consiste em permitir a exploração econômica dos recursos naturais de maneira racional e sem desperdício (Shigunov Neto et al., 2009).

Neste contexto, o presente estudo busca verificar como os conflitos no uso do solo e o uso inadequado dos recursos naturais, não atentando para a legislação ambiental, interferem no sucesso das medidas para a conservação ambiental, usando como base um estudo de caso de uma propriedade rural localizada no interior de Minas Gerais. Os objetivos específicos visam relatar o uso inadequado do solo, realizar um estudo sobre a aplicação da Legislação ambiental e propor soluções de recuperação da área degradada pelo uso inadequado do solo.

Diante disso, justifica-se a importância do estudo uma vez que se faz necessário utilizar os recursos naturais com base na legislação ambiental vigente, para que não seja feito o uso inadequado, contribuindo para o desenvolvimento socioeconômico da população e para a conservação ambiental.

\section{A Política Nacional do Meio Ambiente}

A Lei no 6.938/1981 trata da Política Nacional do Meio Ambiente, que foi recepcionada pela Constituição Federal e objetiva preservar, melhorar e recuperar a qualidade ambiental propícia a vida, assegurando o desenvolvimento socioeconômico, interesses de segurança nacional e a proteção da dignidade da vida humana. A Lei constitui ainda o Sistema Nacional do Meio Ambiente (Sisnama) e institui o Cadastro de Defesa Ambiental (Brasil, 1981). 
Alguns princípios devem ser atendidos ao se buscar estes objetivos, como (a) a manutenção do equilíbrio ecológico, considerando o meio ambiente como um patrimônio público, (b) a racionalização do uso do solo, do subsolo, da água e do ar, (c) o planejamento e fiscalização do uso dos recursos ambientais, (d) a proteção dos ecossistemas, (e) o controle e o zoneamento das atividades potencial ou efetivamente poluidoras, (f) os incentivos à pesquisa de tecnologias para o uso racional e a proteção dos recursos ambientais, (g) o acompanhamento do estado da qualidade ambiental, (h) a recuperação de áreas degradadas e a proteção de áreas ameaçadas de degradação, e (i) a educação ambiental para todos os níveis do ensino estendendo, também, para a comunidade (Brasil, 1981).

A Política Nacional do Meio Ambiente estabelece critérios e padrões de qualidade ambiental e de normas relativas ao uso e manejo dos recursos ambientais. A política traz, também, a obrigação do poluidor recuperar e/ou indenizar os danos causados por suas atividades (Brasil, 1981).

O Sistema Nacional do Meio Ambiente (SISNAMA) constitui-se de órgãos e entidades da União, dos Estados, do Distrito Federal, dos Territórios e dos Municípios, também de fundações instituídas pelo Poder Público, responsáveis pela proteção e melhoria da qualidade ambiental (Brasil, 1981).

Dentro da estruturação do SISNAMA, encontramos o Conselho Nacional do Meio Ambiente (CONAMA), que é o órgão consultivo e deliberativo, tendo como função assessorar e propor ao Conselho de Governo, diretrizes de políticas governamentais para as questões ambientais e deliberar sobre normas e padrões compatíveis com o meio ambiente ecologicamente equilibrado e essencial à sadia qualidade de vida. Por sua vez, o Instituto Brasileiro do Meio Ambiente e dos Recursos Naturais Renováveis (IBAMA) e o Instituto Chico Mendes de Conservação da Biodiversidade (ICMBio) são órgãos executores, tendo a função de executar e fazer executar a política e as diretrizes governamentais fixadas para o meio ambiente (Brasil, 1981).

O CONAMA estabelece, mediante proposta do IBAMA, normas e critérios para o licenciamento de atividades efetiva ou potencialmente poluidoras; determina a realização de estudos das alternativas e das possíveis consequências ambientais de projetos; estabelecer normas, critérios e padrões relativos ao controle e à manutenção da qualidade do meio ambiente com vistas ao uso racional dos recursos ambientais (Brasil, 1981).

O CONAMA estabeleceu por meio de suas resoluções os instrumentos da Política Nacional do Meio Ambiente, que são mecanismos utilizados para que os objetivos da política sejam alcançados. Dentre esses, o zoneamento ambiental aparece como uma intervenção estatal a fim de possibilitar o uso ordenado do território (Mendes, 2015). Compete ao Município a função de ordenar o território quanto ao uso e ocupação do solo (Brasil, 1988).

\section{A lei florestal de Minas Gerais}

A Lei no 20.922/2013, do Estado de Minas Gerais, trata das políticas florestal e de proteção à biodiversidade que envolvem ações para o uso sustentável dos recursos naturais e para a conservação do meio ambiente ecologicamente equilibrado, essencial a qualidade de vida (Minas Gerais, 2013).

Esta lei trata da política florestal e da proteção da biodiversidade do Estado, incluindo, portanto, o Sistema Estadual de Unidades de Conservação. A lei florestal mineira traz regras que correspondem à Lei no 12.651/2012 (Brasil, 2012) e ao Sistema Nacional de Unidades de Conservação, a Lei no 9.985/2000 (Brasil, 2000). Nas áreas de Mata Atlântica, aplicam-se integralmente as regras estabelecidas na Lei da Mata Atlântica, a Lei no 11.428/2006 (Bedê, 2013). 
A Lei no 12.651/2012 criou o Cadastro Ambiental Rural (CAR) e o Programa de Recuperação Ambiental (PRA) que são instrumentos para a regularização ambiental das propriedades rurais (Bedê, 2013).

O CAR consiste em um registro público eletrônico nacional, obrigatório para os imóveis rurais, visando a integrar as informações ambientais das propriedades rurais e compor uma base de dados para ações ambientais. O PRA consiste no Programa de Recuperação Ambiental cabendo a União e aos estados a sua implantação. Os estados devem detalhar o programa, que objetiva a regularização ambiental das propriedades rurais (Bedê, 2013).

As áreas de preservação permanente (APP) são áreas cobertas ou não por vegetação nativa, com a função de preservar os recursos hídricos, a paisagem, a estabilidade geológica e a biodiversidade, facilitar o fluxo gênico de fauna e flora, proteger o solo e assegurar o bem-estar das populações humanas (Minas Gerais, 2013).

Em termos gerais, são áreas de preservação permanente em zonas rurais ou urbanas (a) as faixas marginais de cursos d'água naturais perenes e intermitentes, (b) as áreas em torno dos lagos e lagoas naturais e dos reservatórios artificiais, (c) as áreas no entorno das nascentes e dos olhos d'água perenes, (d) as encostas íngremes, (e) as bordas dos tabuleiros ou chapadas, (f) os topos de morros, montes, montanhas e serras, com altura mínima de cem metros e inclinação média maior que vinte e cinco graus, (g) as áreas em altitude superior a mil e oitocentos metros, e (h) as veredas (Minas Gerais, 2013).

A vegetação situada em áreas de preservação permanente deve ser mantida pelo proprietário da área e caso ocorra a supressão, é obrigatória a recomposição da vegetação. Esta obrigação é transmitida ao sucessor no caso de transferência da posse do imóvel rural. A intervenção em áreas de preservação permanente pode ser autorizada pelo órgão ambiental em casos de utilidade pública, interesse social ou atividades de baixo impacto ambiental (Minas Gerais, 2013).

Em área rural consolidada, definida como área de imóvel rural com ocupação antrópica preexistente a 22 de julho de 2008, é autorizada a continuidade das atividades agrossilvipastoris, de ecoturismo e de turismo rural (Minas Gerais, 2013).

A reserva legal é a área localizada no interior de uma propriedade rural com a função de assegurar o uso econômico sustentável dos recursos naturais ali presentes, auxiliar a conservação e a reabilitação dos processos ecológicos e da biodiversidade, abrigar e proteger a fauna e flora nativas. Nela devem ser mantidas no mínimo $20 \%$ da área total do imóvel com cobertura de vegetação nativa não sendo permitida a alteração do uso do solo. A reserva legal pode ser sobreposta às áreas de preservação permanente desde que essa sobreposição não libere novas áreas para o uso alternativo do solo. A reserva legal deve ser registrada por meio de inscrição do imóvel no Cadastro Ambiental Rural (Minas Gerais, 2013).

O proprietário de imóvel rural com mais de quatro módulos fiscais (o módulo fiscal é uma unidade de medida agrária, expressa em hectares) que em 22 de julho de 2008 possuía área de Reserva Legal menor que $20 \%$ da sua área total, deve recompor a Reserva Legal através da condução da regeneração natural da vegetação; do plantio de espécies nativas locais; ou da compensação por outra área conservada (Minas Gerais, 2013).

A compensação pode ser feita em área de tamanho equivalente à área a ser compensada, através de (a) Cotas de Reserva Ambiental (CRA) que são títulos representativos de cobertura vegetal (nativa) em outra propriedade, (b) arrendamento de área sob regime de servidão ambiental, que consiste na limitação do uso da propriedade com a finalidade de preservar, conservar ou recuperar os recursos ambientais existentes, ou reserva legal, (c) doação ao poder público de propriedade localizada no interior de uma unidade de conservação pendente de regularização fundiária, (d) cadastramento de outra 
área equivalente, do mesmo proprietário, localizada no mesmo bioma (Minas Gerais, 2013).

\section{A Lei da Mata Atlântica}

A Lei no 11.428/2006 dispõe sobre a vegetação nativa do Bioma Mata Atlântica e sua conservação, proteção, regeneração e utilização. 0 objetivo geral da Lei é o desenvolvimento sustentável e, os objetivos específicos, constituem-se da proteção da biodiversidade, da saúde humana, dos valores paisagísticos, estéticos e turísticos, do regime hídrico e da estabilidade social. Apenas os remanescentes da vegetação no estágio primário e nos estágios secundário inicial, médio e avançado de regeneração terão seu uso e conservação regulados (Brasil, 2006).

Para os efeitos dessa lei, consideram-se as seguintes formações florestais nativas e ecossistemas associados: Floresta Ombrófila Densa; Floresta Ombrófila Mista (Mata de Araucárias); Floresta Ombrófila Aberta; Floresta Estacional Semidecidual; e Floresta Estacional Decidual. Também, os manguezais, as restingas, campos de altitude, brejos interioranos e encraves florestais do Nordeste (Brasil, 2006).

A Lei define o pequeno produtor rural como aquele que reside na zona rural e cuja extensão da propriedade não seja superior a cinquenta hectares, explorando-a mediante o trabalho pessoal, de sua família e, eventualmente, com a ajuda de terceiros. Também, consideram-se as posses coletivas onde a fração individual não seja superior a cinquenta hectares, sendo a renda bruta proveniente de atividades agrícolas, pecuárias ou silviculturais ou do extrativismo rural em, no mínimo, oitenta por cento (Brasil, 2006).

A exploração de espécies da flora nativa, para consumo nas propriedades dos pequenos produtores rurais, sem propósito comercial, independe de autorização dos órgãos competentes, sendo que estes órgãos devem assistir os produtores no manejo e exploração sustentáveis da flora nativa (Brasil, 2006).

A supressão de vegetação primária e secundária no estágio avançado de regeneração poderá ser autorizada em caso de utilidade pública. A vegetação secundária em estágio médio de regeneração poderá ser suprimida nos casos de utilidade pública e interesse social, quando não houver alternativa técnica e locacional para 0 empreendimento. Devendo ser autorizadas pelo órgão ambiental estadual competente, com anuência prévia, quando couber, do órgão federal ou municipal de meio ambiente. Na possibilidade de atividade potencialmente causadora de significativa degradação do meio ambiente, o órgão competente exigirá a elaboração de Estudo Prévio de Impacto Ambiental (Brasil, 2006).

A supressão de vegetação primária ou secundária nos estágios médio ou avançado de regeneração condiciona-se à compensação ambiental, sendo destinada área equivalente à extensão da área desmatada, com as mesmas características ecológicas e na mesma bacia hidrográfica, preferencialmente, na mesma microbacia hidrográfica. Impossibilitada essa compensação, o órgão exigirá a reposição florestal, com espécies nativas, também em área equivalente à desmatada, na mesma bacia hidrográfica, preferencialmente, na mesma microbacia (Brasil, 2006).

O poder público incentivará, economicamente, a proteção e o uso sustentável da Mata Atlântica, observando as seguintes características da área: importância e representatividade do ecossistema; presença de fauna e flora ameaçadas de extinção; recursos hídricos; valor paisagístico, estético e turístico; respeito à legislação ambiental; capacidade de uso real e produtividade atual (Brasil, 2006).

A conservação da vegetação nativa em regeneração do Bioma Mata Atlântica em imóvel rural ou urbano cumpre função social e é de interesse público. Os proprietários podem usar as áreas sujeitas a restrição pela Lei da Mata Atlântica para a Reserva Legal e seu excedente como compensação ambiental ou instituição de Cota de Reserva Ambiental CRA (Brasil, 2006). 


\section{O uso e ocupação dos solos}

Segundo a Lei no 6.766/1979, que dispõe sobre o parcelamento do solo urbano, os estados, o distrito federal e os municípios poderão estabelecer normas referentes ao parcelamento do solo municipal. Compete ao município a função de ordenar o território quanto ao uso e ocupação do solo (Brasil, 1979; Brasil, 1988).

0 parcelamento do solo urbano poderá ser feito mediante loteamento ou desmembramento. Somente será admitido o parcelamento do solo para fins urbanos em zonas urbanas definidas pelo plano diretor ou aprovadas por lei municipal. A legislação municipal definirá os usos permitidos e ocupação do solo (Brasil, 1979).

Todas as atividades humanas são formas de uso e ocupação do solo. 0 uso e a ocupação do solo de forma inadequada ocasionam diversos problemas ambientais e traz prejuízos para o solo, para a vegetação e para a população rural, contribuindo assim com o baixo nível socioeconômico de pequenos proprietários rurais (Santos, 2009).

A antropização recorrente do meio ambiente junto ao uso indevido do solo é responsável pelas pressões sobre os recursos naturais. Ações como a especulação imobiliária e expansão urbana, a abertura de grandes pastagens, a agricultura convencional, o extrativismo desordenado, a poluição, a formação de lagos para hidroelétricas e mineração de superfície são alguns exemplos de uso do solo que causam a degradação e a fragmentação dos ambientes naturais sendo responsáveis diretos pela extinção de espécies (Viana e Pinheiro, 1998).

O conhecimento sobre o uso e ocupação do solo é crucial para o planejamento da utilização racional dos recursos naturais. Monitorar as modificações de uso e ocupação das terras contribui para avaliar a sustentabilidade ambiental, principalmente em áreas com uso predominantemente agrícola (Ferreira e Lacerda, 2006).

O Sistema de Informações Geográficas (SIG) é uma importante ferramenta usada no levantamento do uso do solo de uma bacia hidrográfica. Ele consiste no tratamento computacional de dados geográficos, os quais são capazes de englobar diversos projetos nas áreas ambientais (Santos, 2009).

\section{Legislação municipal}

No que se refere à estrutura administrativa de Meio Ambiente, Desterro de Entre Rios não possuiu Secretaria de Meio Ambiente, apenas um Conselho Municipal de Meio Ambiente de caráter consultivo. A prefeitura não mantém acordo administrativo que delegue atribuição de Meio Ambiente para o órgão estadual. Não há legislação específica municipal para a questão ambiental (IBGE, 2002).

A Lei Orgânica de Desterro de Entre Rios apresenta na seção de meio ambiente as atribuições municipais relacionadas ao tema. Cabe ao município, dentre outras, a prevenção e o controle da poluição, da erosão, do assoreamento e de outras formas de degradação ambiental; a preservação dos recursos naturais; a criação e a manutenção de unidades de conservação; o estímulo e a promoção de reflorescimento com espécies nativas objetivando especialmente a proteção de encostas e dos recursos hídricos; e o registro, o acompanhamento e a fiscalização das concessões de direitos de pesquisa e exploração de recursos hídricos e minerais (Desterro de Entre Rios, 1990).

O licenciamento ambiental está sujeito à prévia anuência do órgão municipal de controle e política ambiental. Dependerá, no caso de atividade ou obra potencialmente causadora de significativa degradação do meio ambiente, de prévio relatório de impacto ambiental, seguido de audiência pública para informação e discussão sobre o projeto. Aos responsáveis pela exploração de recursos minerais, cabe a recuperação do ambiente degradado, de acordo com solução técnica previamente indicada pelo órgão municipal de controle e política ambiental. 0 ato lesivo ao meio ambiente sujeitará a interdição temporária ou definitiva das atividades e a obrigação de recuperar o dano, sendo o infrator pessoa física ou jurídica (Desterro de Entre Rios, 1990). 
A seção de Política Urbana objetiva o pleno desenvolvimento das funções sociais da cidade e o bem-estar da população. Alguns aspectos que ajudarão atingir esses objetivos são o planejamento urbano e a integração e complementaridade das atividades urbanas e rurais. O Plano Diretor, a Legislação de parcelamento, ocupação e uso do solo são alguns instrumentos do Planejamento Urbano (Desterro de Entre Rios, 1990).

A Lei Orgânica aponta que Plano Diretor deverá ser aprovado pela maioria dos membros da câmara e conterá as diretrizes econômicas, financeiras, administrativas, sociais, de uso e ocupação do solo, de preservação do patrimônio ambiental e cultural. Ele definirá áreas especiais, como as Áreas de urbanização que são regiões de preservação ambiental onde a ocupação deve ser desestimulada ou contida (Desterro de Entre Rios, 1990).

A seção de Política Rural define que o município deve fazer estudos a fim de conhecer as características e potencialidades de sua zona rural visando à criação de unidades de conservação ambiental; a preservação da cobertura vegetal de proteção das encostas, nascentes e cursos d'água; propiciar refúgio à fauna; proteger e preservar os ecossistemas; garantir a perpetuação de bancos genéticos; implantar projetos florestais e parques naturais; e ampliar as atividades agrícolas (Desterro de Entre Rios, 1990).

\section{Material e métodos}

\section{Área de estudo}

Desterro de Entre Rios é um município localizado no estado de Minas Gerais, região sudeste do Brasil. Encontra-se na mesorregião metropolitana de Belo Horizonte e na microrregião de Conselheiro Lafaiete. Possui uma área de $377,165 \mathrm{~km}^{2}$ e tem uma população composta de cerca de 7.000 habitantes. 0 bioma predominante é a Mata Atlântica e o município participa do Comitê de Bacia Hidrográfica do Rio Pará e do Comitê de Bacia Hidrográfica do Rio Paraopeba. Ambos são comitês de afluentes da Bacia do Rio São Francisco (IBGE, 2010; IGAM, 2018).

As bacias hidrográficas são usadas como unidade física de avaliação das alterações ocorridas no ambiente, pois seus limites são imutáveis dentro do horizonte de planejamento humano, o que facilita o acompanhamento das alterações naturais ou introduzidas pelo homem na área (Vaeza et al, 2010).

A área de estudo está inserida na Bacia Hidrográfica do Rio Pará (UPGRH SF2) que integra a Região Hidrográfica do Alto São Francisco, na Bacia do Rio São Francisco, pela margem direita. O Município de Desterro de Entre Rios faz parte da Bacia Alto Rio Pará, sendo que a área de estudo está inserida na Microbacia do Ribeirão Capela Nova (CERN, 2018).

A Bacia Hidrográfica do Rio Pará possuiu uma área de drenagem de $12.233 \mathrm{~km}^{2}$, abrangendo 35 municípios. A atividade econômica dominante na Sub-Bacia do Alto Rio Pará é a mineração, sendo que a agricultura e pecuária são, também, atividades importantes desenvolvidas (Minas Gerais, 2013).

A propriedade rural objeto deste estudo de caso, o Sítio Barro Preto, encontra-se sob as coordenas geográficas de referência $20^{\circ} 39^{\prime} 38,4^{\prime \prime} \mathrm{S}$ e $44^{\circ} 20^{\prime} 51,3^{\prime \prime}$ W (Figura 1). Sua extensão é de 49,53 ha, tratando-se da zona rural do Município de Desterro de Entre Rios.

A Figura 1 apresenta a vista aérea da área de estudo, evidenciando a localização do Sítio Barro Preto com as coordenadas geográficas marcadas. 


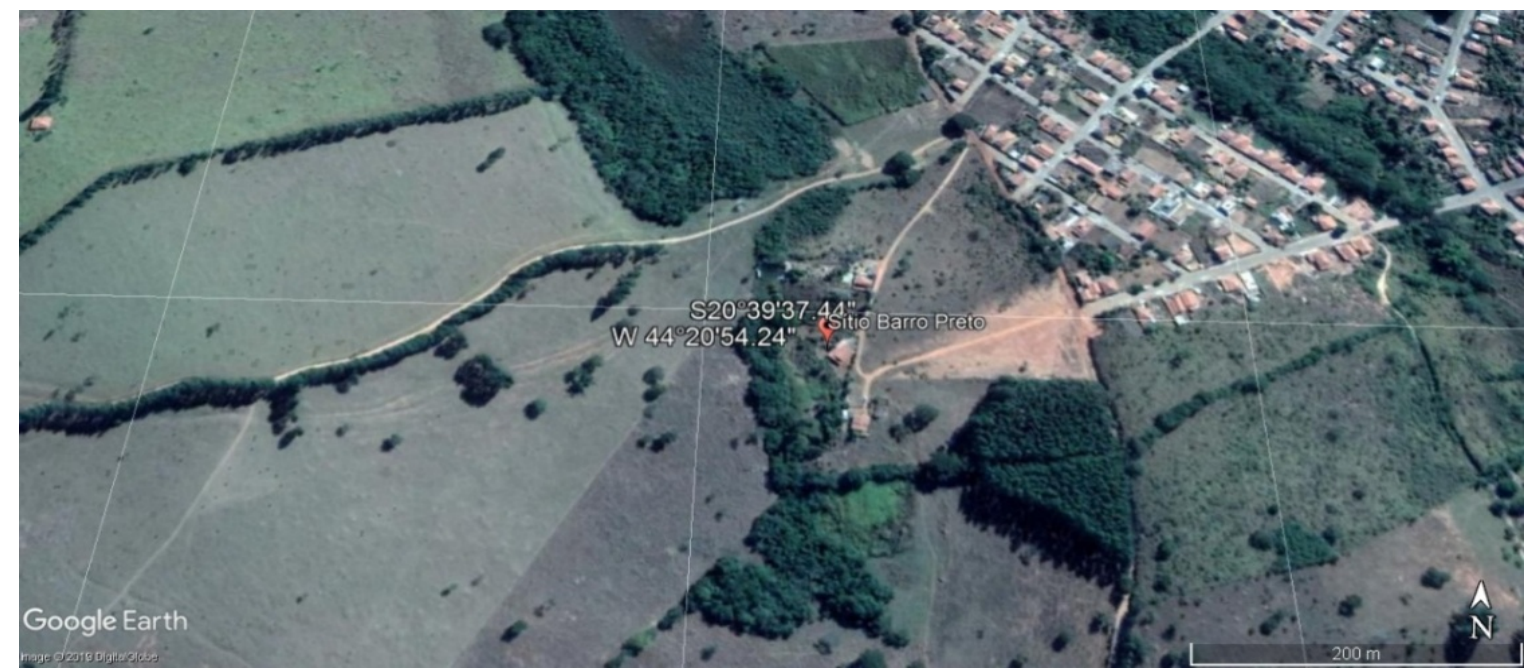

Figura 1. Sítio Barro Preto e região. Fonte: Google Earth.

As coordenadas foram definidas através do Google Earth, onde foi feita uma busca nominal pelo município e identificada a região da propriedade rural. Posteriormente, o arquivo foi exportado para estudo da região através da plataforma da Infraestrutura de Dados Espaciais do Sistema Estadual de Meio Ambiente e Recursos Hídricos (IDE-Sisema).

\section{IDE-Sisema}

A Infraestrutura de Dados Espaciais do Sistema Estadual de Meio Ambiente e Recursos Hídricos (IDE-Sisema), é uma plataforma instituída pela Resolução Conjunta SEMAD/FEAM/IEF/IGAM no 2.466/2017 (Minas Gerais, 2017) e atualizada pela Resolução Conjunta SEMAD/FEAM/IEF/IGAM no 2.631/2018 (Minas Gerais, 2018), que objetiva a organização dos processos de geração, armazenamento, acesso, compartilhamento, disseminação e uso dos dados geoespaciais resultantes das atividades, programas e projetos ambientais e de recursos hídricos desenvolvidos pelo Sisema (Comitê Gestor do IDE-Sisema, 2018).

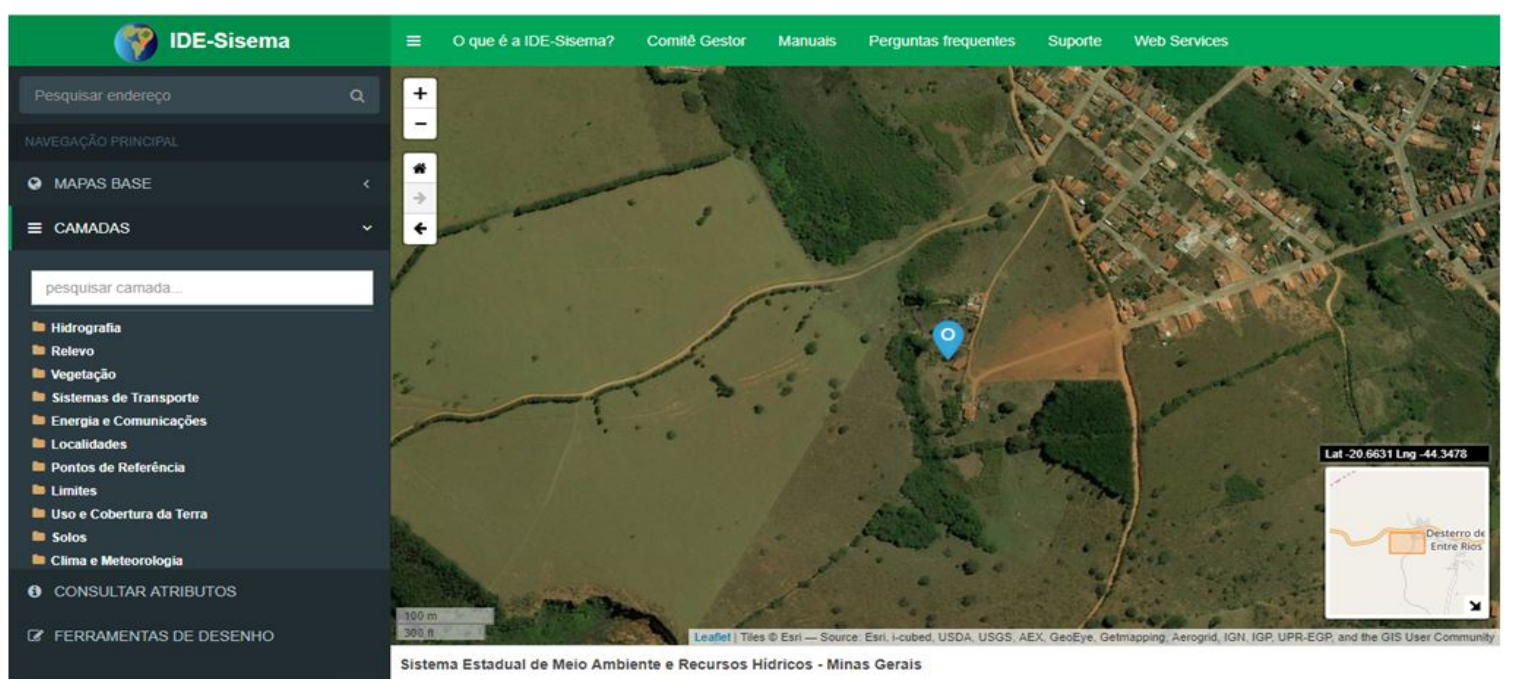

Figura 2. Sítio Barro Preto e Região na plataforma IDE-Sisema. Fonte: IDE-Sisema. 
A Infraestrutura de Dados Espaciais conta com um Sistema de Informação Geográfica em plataforma online para possibilitar o acesso aos dados oficiais do Sisema. A Plataforma IDE-Sisema proporciona uma visão integrada do território de Minas Gerais, através da visualização dos atributos ambientais e antrópicos, bem como de restrições ambientais legalmente instituídas (Comitê Gestor do IDE-Sisema, 2018).

0 arquivo digital da propriedade foi gerado através do programa "em formato kml" e submetido às camadas da plataforma IDE-Sisema a fim de se conhecer os atributos da região e definir quais as legislações ambientais a área está sujeita (Figura 2).

\section{Resultados e discussão}

A visita in loco permitiu a identificação de diversos tipos de uso do solo na propriedade, tais como áreas antropizadas composta por residência, plantações de horta e pomar, e, ao fundo da propriedade após a ruína de um engenho, ambientes naturais ocupados por um remanescente de Mata Atlântica e uma área brejosa (Figura 3 e Figura 4). A propriedade é cortada por um pequeno córrego intermitente que nasce em uma região da vizinhança conhecida por Matinha. Este córrego foi canalizado e coberto por terra desde a proximidade de sua nascente, atravessando os limites de algumas propriedades, inclusive do sítio deste estudo de caso sem a autorização do proprietário, até uma propriedade adjacente. Esta intervenção foi feita por um morador da região que teve por objetivo o represamento desta água, para a criação de um lago artificial, em sua propriedade.

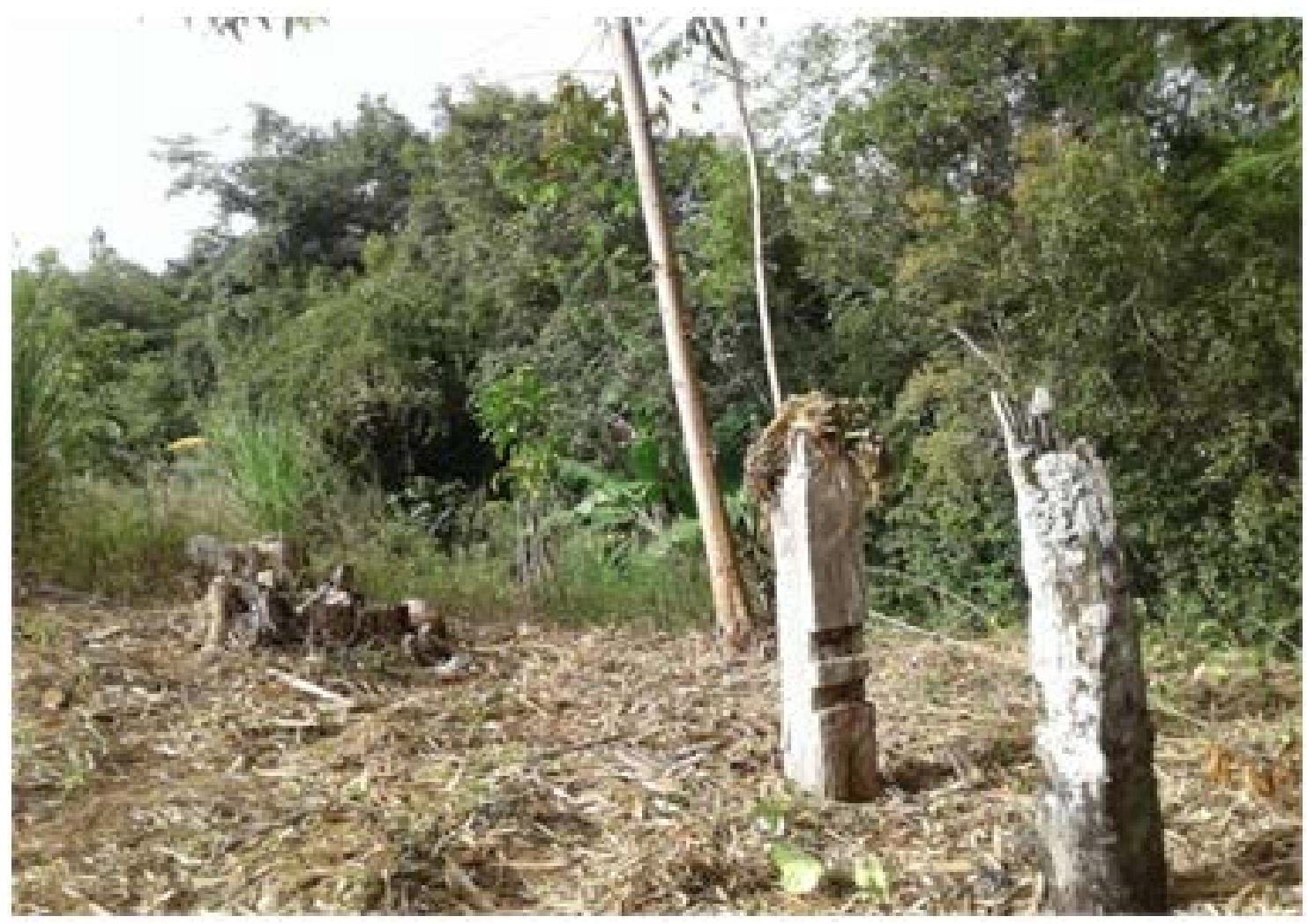

Figura 3. Mata preservada atrás da ruína de engenho. 


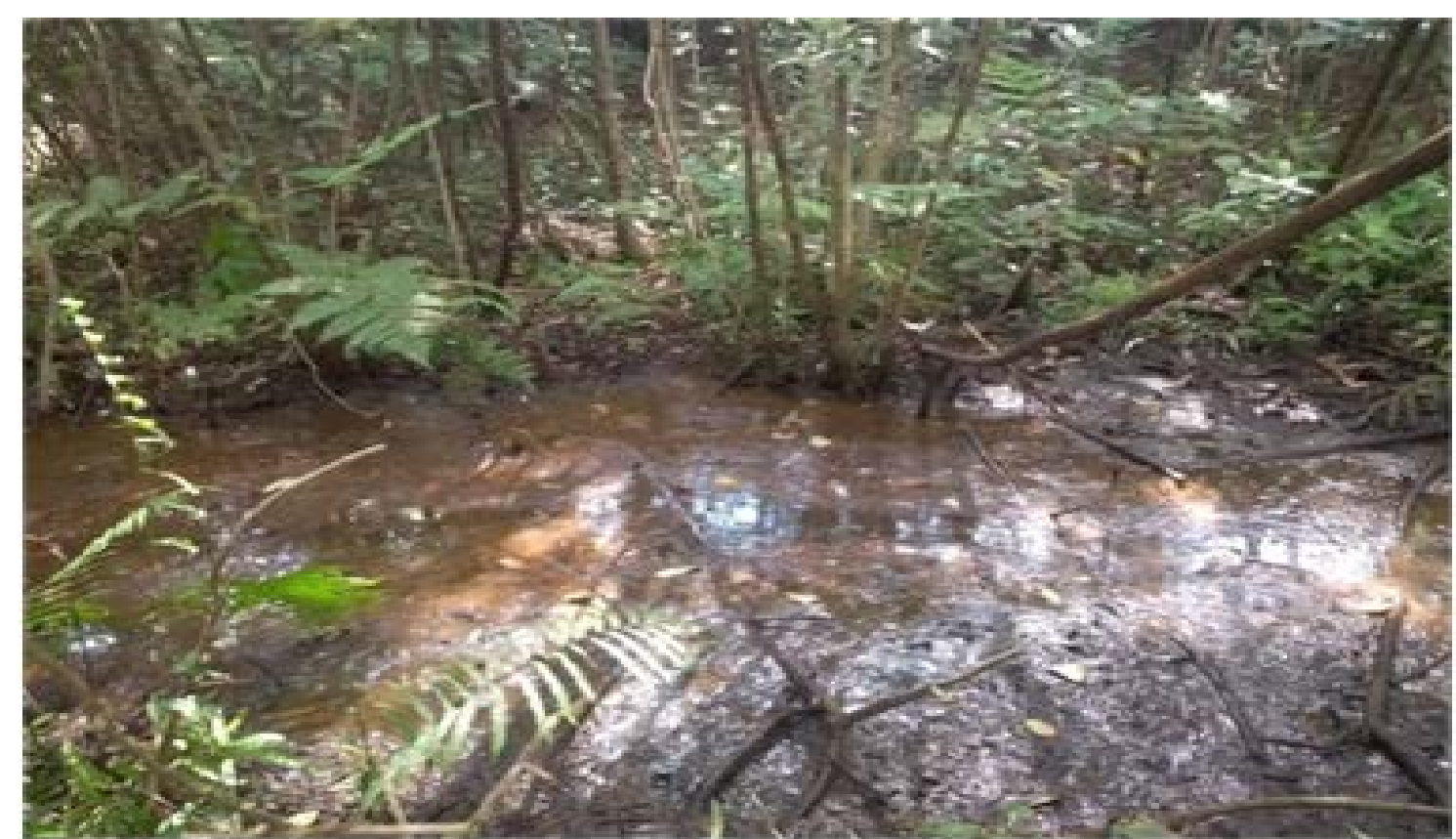

Figura 4. Interior da área brejosa preservada.

A análise geoespacial do município e da propriedade através das camadas da plataforma IDE-Sisema, permitiu delinear melhor as características da região estudada. 0 município está inserido no Bioma Mata Atlântica (Figura 5), em um mosaico de agropecuária com remanescentes florestais e, também, há presença de atividade minerária em seus domínios.

A análise permite inferir, também, que a região da área de estudo trata-se de uma área prioritária para recuperação, sendo a prioridade classificada como muito alta (Figura 6), pois o componente natural do bioma Mata Atlântica é muito precário em todo o município, a erodibilidade do solo é alta e, há, ainda, alta disponibilidade de água subterrânea (Figura 7) e superficial (Figura 8) na região.

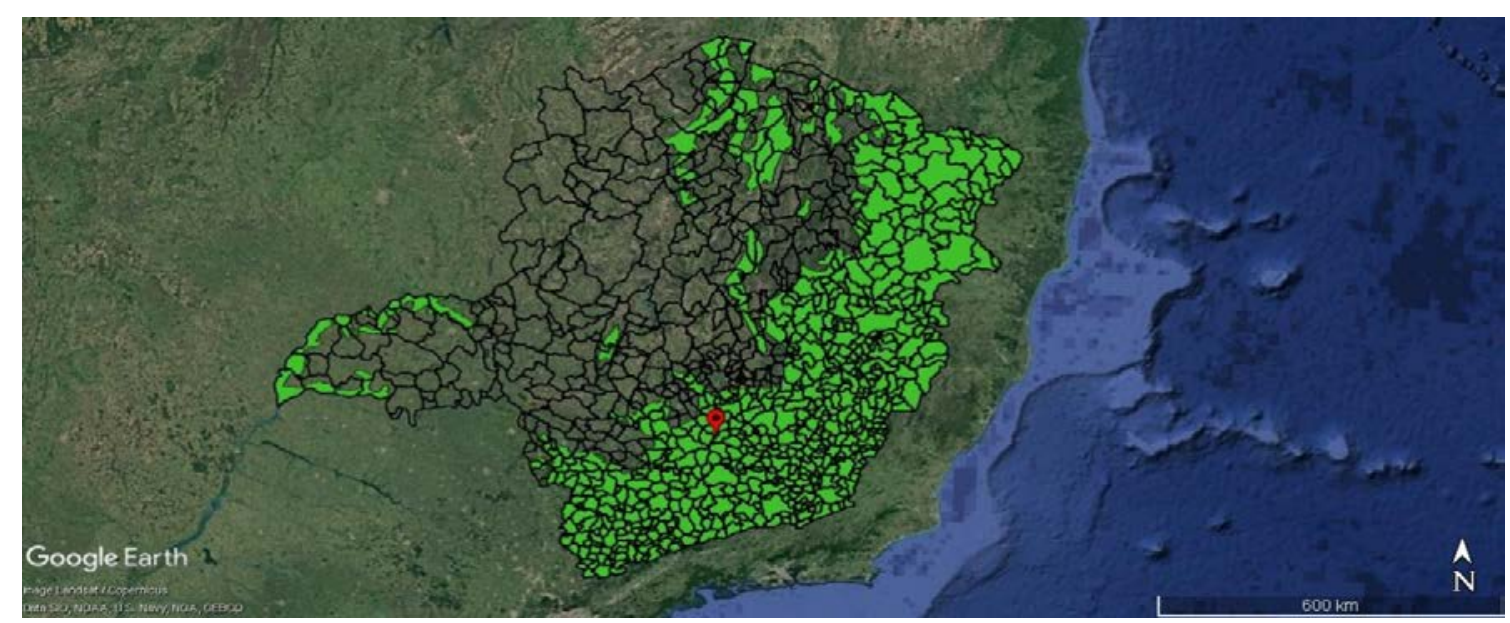

Figura 5. Bioma Mata Atlântica no estado de Minas Gerais com o município demarcado. Fonte: Adaptado do IDE-Sisema e Google Earth. 


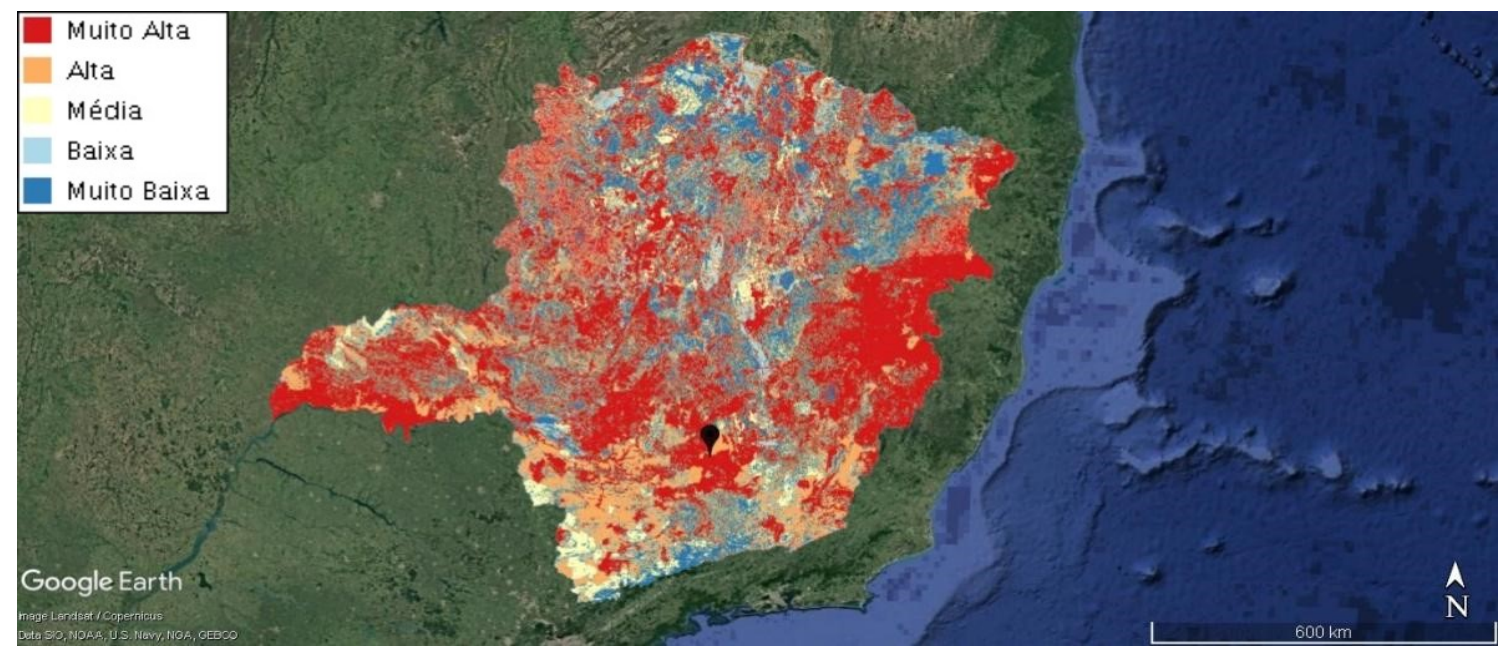

Figura 6. Áreas prioritárias para a recuperação em MG com o município demarcado. Fonte: Adaptado do IDE-Sisema e Google Earth.

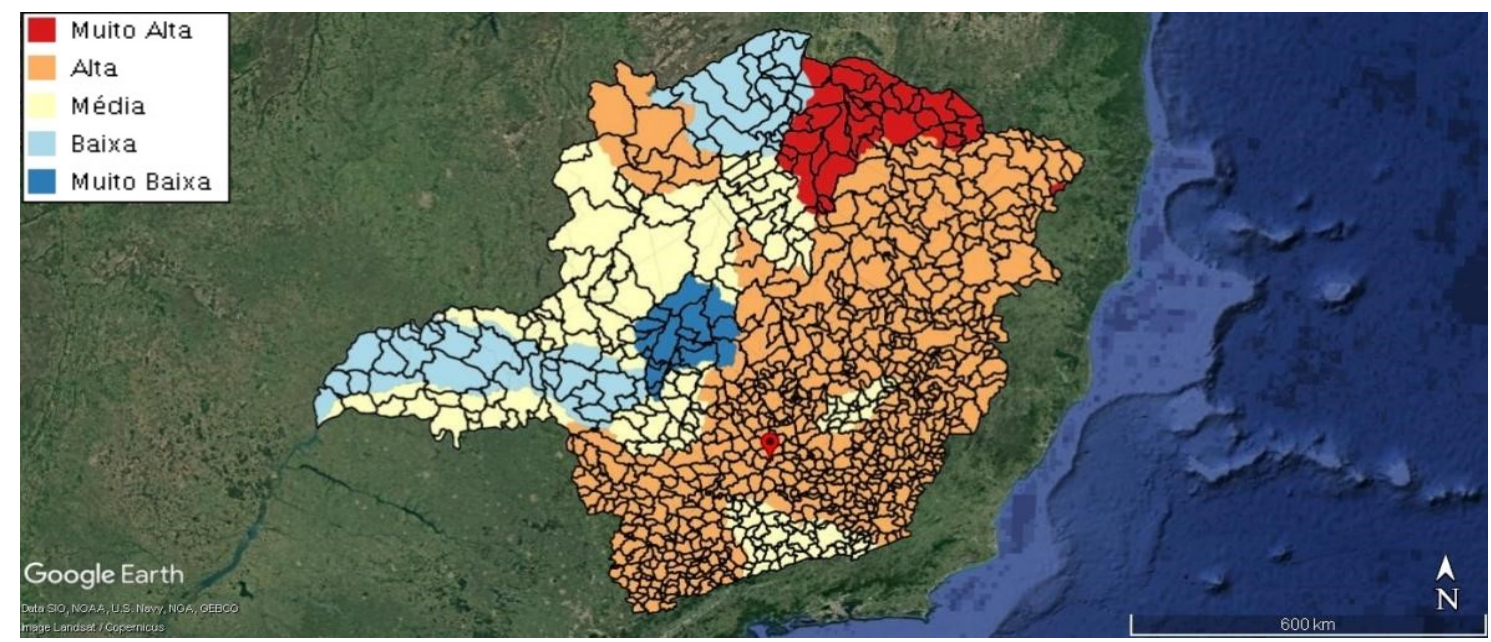

Figura 7. Alta disponibilidade de água subterrânea. Fonte: Adaptado do IDE-Sisema e Google Earth.

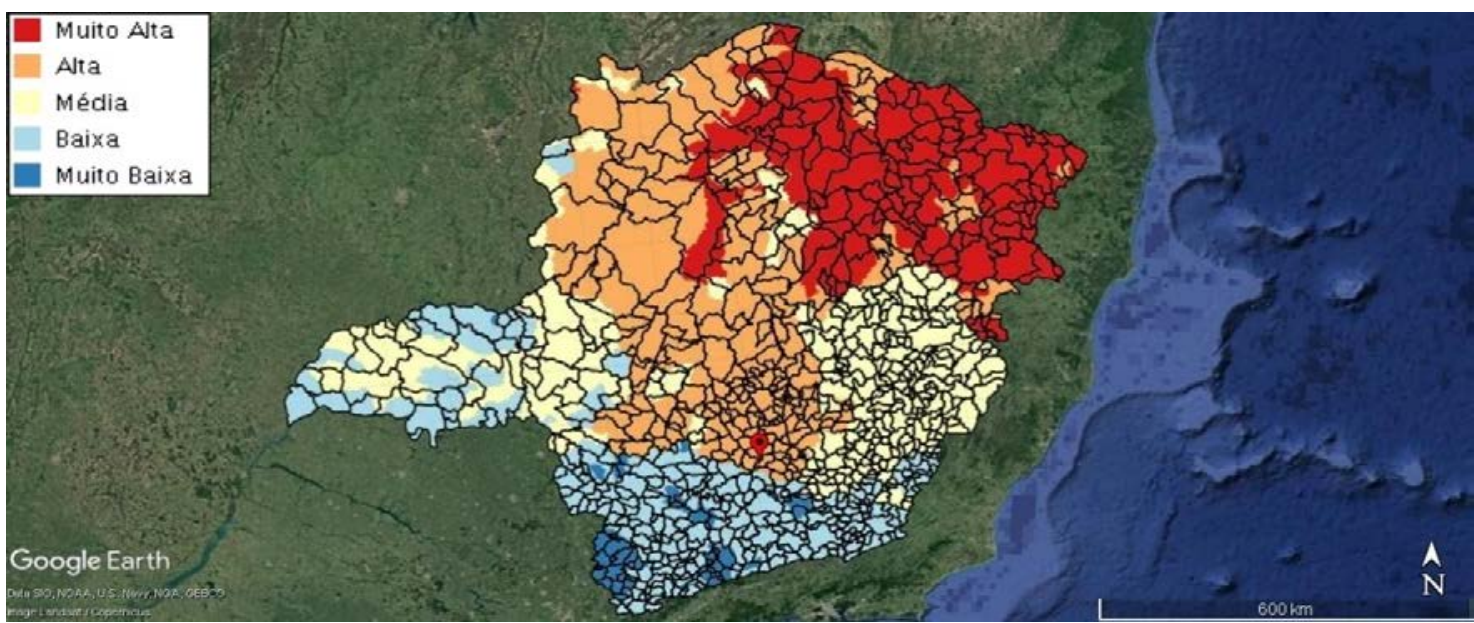

Figura 8. Alta disponibilidade de água superficial. Fonte: Adaptado do IDE-Sisema e Google Earth. 
A Política Nacional do Meio Ambiente (Lei no 6.938/1981) preconiza sobre a necessidade da manutenção do equilíbrio ecológico, atentando para a racionalização no uso dos recursos naturais, a proteção dos ecossistemas e recuperação das áreas degradadas (Brasil, 1981). Neste contexto, a legislação ambiental aplica-se aos tipos de uso do solo para ocupação das áreas rurais, buscando aliar desenvolvimento socioeconômico à conservação ambiental tendo em vista a relevância dos recursos naturais.

A Lei Florestal Estadual de Minas Gerais traz regras que correspondem à Lei $n^{0}$ 12.651/2012 (Brasil, 2012) e ao Sistema Nacional de Unidades de Conservação (SNUC) (Lei no 9.985/2000) (Brasil. 2000). Assim, define que área rural consolidada é a área de imóvel rural com ocupação antrópica preexistente a 22 de julho de 2008, sendo autorizada a continuidade das atividades já existentes. A propriedade objeto do estudo existe desde meados do século XX e foi adquirida pelo atual proprietário na década de 1990. Desde sempre, consiste de um minifúndio de uso familiar e doméstico.

A lei florestal apresenta as áreas de preservação permanente (APP), cuja função é preservar os recursos naturais em zonas rurais e urbanas. As análises mostram que o município insere-se no bioma Mata Atlântica, em um mosaico de agropecuária com remanescentes florestais. Ainda, a área é considerada prioritária para recuperação devido à Mata Atlântica ser um hotspot de conservação da biodiversidade e apresentar o componente natural do bioma muito precário na região. Diante disso, a propriedade apresenta regiões que se enquadram nos critérios de áreas de preservação permanente.

Por tratar-se de um minifúndio, propriedade rural de tamanho inferior a 1 módulo fiscal, equivalente a 30 ha (INCRA, 2018), a recomposição das faixas marginais do curso d'água canalizado indevidamente, deve ser feita com espécies nativas e respeitando a largura mínima de cinco metros de vegetação preservada, a partir das margens do leito natural do córrego intermitente, livre das intervenções antrópicas. A área de mata nativa de aspecto brejoso e com a presença de olho d'água intermitente deve permanecer preservada.

Ressalta-se que a lei florestal determina que a propriedade, cujo tamanho é inferior a quatro módulos fiscais, deve ser inscrita no Cadastro Ambiental Rural (CAR), um registro eletrônico nacional obrigatório para todos os imóveis rurais, que integra as informações ambientais das propriedades rurais em uma base de dados para ações ambientais. A propriedade deve ser inscrita, considerando a reserva de mata nativa, já existente na data de 22 de julho de 2008, para fins de reserva legal, sendo proibidas novas intervenções para uso alternativo do solo.

A alta disponibilidade de água subterrânea e superficial no município propicia a criação de áreas de preservação permanente. Ainda, a região é composta por solos de alta erodibilidade, vulneráveis a erosão e a cobertura vegetal preservada nas áreas de preservação permanente é essencial na prevenção da perda do solo e da água. As áreas de preservação permanente são o meio mais seguro e eficaz na preservação e manutenção da qualidade dos recursos hídricos.

\section{Considerações finais}

As atividades agrárias são comuns nos municípios do interior do Brasil, representando uma boa parcela do produto interno bruto (PIB) nacional. Além disso, são uma importante forma de uso e ocupação do solo e, também, uma fonte causadora de impactos ambientais de diversas proporções.

Historicamente, na zona rural estudada, predominam pequenas propriedades familiares, de trabalhadores rurais, que há gerações usam o solo para agricultura de subsistência e pastagem. Assim, é comum a plantação de árvores frutíferas, cana-de-açúcar para alimentar o gado e uso dos córregos para a dessedentação desses animais. 
Podemos concluir que, com base nos resultados obtidos no presente trabalho, a legislação ambiental não é de pleno entendimento para muitas dessas pessoas que continuam a usar a terra da forma como aprenderam durante a vida, gerando problemas ambientais que fogem aos limites de sua propriedade, mesmo que nem sempre seja de forma intencional. Mas o Meio Ambiente é um patrimônio público, garantido pela Constituição Federal, onde a exploração econômica dos recursos naturais deve ser feita de maneira racional, primando pela manutenção dos ecossistemas e conservando o meio ambiente para as gerações presentes e futuras e alegar desconhecimento da lei não é justificativa para não ter que cumpri-la.

A educação ambiental extensiva à comunidade, também garantida pela Constituição, mostra-se necessária, pois é uma poderosa ferramenta na construção do conhecimento, da informação e da conscientização da população quanto aos riscos e consequências ambientais, jurídicas, para a saúde e financeiras que a exploração predatória da natureza pode causar.

As leis ambientais existem para garantir o uso sustentável dos recursos naturais. Ser ambientalmente consciente é necessário para uma produção saudável e de qualidade além de contribuir para a manutenção da vida no planeta, em todas as suas formas. Inclusive a nossa, humana, pois também somos parte integrante do meio ambiente.

\section{Conflito de interesses}

As autoras declaram não haver conflito de interesses.

\section{Referências}

Bedê, JC. Cartilha sobre a nova lei florestal de Minas Gerais: orientações aos produtores rurais. Belo Horizonte: ALMG, 2013. Disponível em: <https://www.almg.gov.br/export/sites/default/consulte/publicacoes_assembleia/cartil has_manuais/arquivos/pdfs/codigo_florestal/cartilha_nova_lei_florestal_completa.pdf>. Acesso em: 14 out. 2019.

Brasil. Lei no 6.766, de 19 de dezembro de 1979. Dispõe sobre o parcelamento do solo urbano e dá outras Providências. Disponível em: <http://www.planalto.gov.br/ ccivil_03/LEIS/L6766.htm>. Acesso em: 15 out. 2019.

Brasil. Lei no 6.938, de 31 de agosto de 1981. Dispõe sobre a Política Nacional do Meio Ambiente, seus fins e mecanismos de formulação e aplicação, e dá outras providências. Disponível em: <http://www.planalto.gov.br/ccivil_03/LEIS/L6938compilada.htm>. Acesso em: 14 out. 2019.

Brasil. Constituição da República Federativa do Brasil 1988. Disponível em: <http://www.planalto.gov.br/ccivil_03/constituicao/ConstituicaoCompilado.htm>. Acesso em: 09 set. 2019.

Brasil. Lei no 9.985, de 18 de julho de 2000. Regulamenta o art. 225, § $1^{\circ}$, incisos I, II, III e VII da Constituição Federal, institui o Sistema Nacional de Unidades de Conservação da Natureza e dá outras providências. Disponível em: <http://www.planalto.gov.br/ ccivil_03/leis/19985.htm>. Acesso em: 14 out. 2019.

Brasil. Lei no 11.428, de 22 de dezembro de 2006. Dispõe sobre a utilização e proteção da vegetação nativa do Bioma Mata Atlântica, e dá outras providências. Disponível em: <http://www.planalto.gov.br/ccivil_03/_Ato2004-2006/2006/Lei/L11428.htm>. Acesso em: 14 out. 2019. 
Brasil. Lei no 12.651, de 25 de maio de 2012. Dispõe sobre a proteção da vegetação nativa; altera as Leis $\mathrm{n}^{\mathbf{0}}$ 6.938, de 31 de agosto de 1981, 9.393, de 19 de dezembro de 1996, e 11.428, de 22 de dezembro de 2006; revoga as Leis nos 4.771, de 15 de setembro de 1965, e 7.754, de 14 de abril de 1989, e a Medida Provisória no 2.166-67, de 24 de agosto de 2001; e dá outras providências. Disponível em: <http://www.planalto. gov.br/ccivil_03/_ato2011-2014/2012/lei/L12651compilado.htm>. Acesso em: 14 out. 2019.

CERN - Consultoria e Empreendimentos de Recursos Naturais. Mina Morro dos Coelhos: Estudo de Impacto Ambiental - EIA. Belo Horizonte: CERN, 2018. Disponível em: <http://www.jmendes.com.br/estudosambientais/EIA/EIA MORRO DOS COELHOS_LOC_VOL II_FN.pdf>. Acesso em: 10 jan. 2020.

Comitê Gestor do IDE-Sisema. Manual 02 - Plataforma online de visualização de camadas de informação geográfica: guia do usuário. Belo Horizonte: SEMAD, 2018. Disponível em: <http://idesisema.meioambiente.mg.gov.br/docs/MANUAL_IDESISEMA_02.pdf $>$. Acesso em: 10 jan. 2020.

Desterro de Entre Rios. Lei Orgânica do Município de Desterro de Entre Rios. 2014. Disponível em: <http://desterrodeentrerios.cam.mg.gov.br/Especifico_Cliente/ 08032530000123/Arquivos/files/Lei_Org\%E2nica.doc_2014\%282\%29.pdf>. Acesso em: 15 out. 2019.

Feltran-Filho, A.; Lima, S. C.; Rosa, R. Mapeamento do uso do solo no Município de Uberlândia-MG, através de imagens TM/LANDSAT. Sociedade \& Natureza, v. 1, p. 127145, 1989.

Ferreira, C. S.; Lacerda, M. P. C. Avaliação temporal do uso e ocupação das terras na Bacia do Rio São Bartolomeu, DF. Brasília: Universidade de Brasília, 2006. (Dissertação de mestrado).

Galatti Filho, F. A. Geoprocessamento aplicado na distribuição espacial da capacidade do uso na microbacia do Córrego dos Rochas, Avaré (SP). Botucatu: Universidade Estadual Paulista Júlio de Mesquita Filho, 2006. (Dissertação de mestrado).

IBGE - Instituto Brasileiro de Geografia e Estatística. Censo demográfico. 2010. Disponível em: <https://cidades.ibge.gov.br/brasil/mg/desterro-de-entre-rios/ panorama>. Acesso em: 01 dez. 2019.

IBGE - Instituto Brasileiro de Geografia e Estatística. Perfil dos municípios brasileiros: meio ambiente. 2002. Disponível em: <http://cidades.ibge.gov.br/brasil/mg/desterro-deentre-rios/pesquisa/10078/70097>. Acesso em: 02 dez. 2019.

IGAM - Instituto Brasileiro de Gestão das Águas. SF2 - CBH Rio Pará. Disponível em: <http://comites.igam.mg.gov.br/comites-estaduais-mg/sf2-para>. Acesso em: $02 \mathrm{dez}$. 2019.

IGAM - Instituto Brasileiro de Gestão das Águas. SF3 - CBH do Rio Paraopeba. Disponível em: <http://comites.igam.mg.gov.br/comites-estaduais-mg/sf3-cbh-do-rio-paraopeba>. Acesso em: 02 dez. 2019.

INCRA - Instituto Nacional de Colonização e Reforma Agrária. Classificação dos imóveis rurais. 2019. Disponível em: <http://www.incra.gov.br/tamanho-propriedades-rurais>. Acesso em: 07 jan. 2020. 
Mendes, N. Política Nacional do Meio Ambiente (PNMA) - Lei no 6938/81- Conceito, objeto e instrumentos. 2015. Disponível em: <https://nathymendes.jusbrasil.com.br/ noticias/321528492/politica-nacional-do-meio-ambiente-pnma-lei-n-6938-81>. Acesso em: 10 out. 2019.

Minas Gerais. Lei no 20.922, de 16 de outubro de 2013. Dispõe sobre as políticas florestal e de proteção à biodiversidade no Estado. Disponível em: <https://www.almg.gov.br/consulte/legislacao/completa/completa-novamin.html?tipo=Lei\&num=20922\&ano=2013 > . Acesso em: 14 out. 2019.

Minas Gerais. Resolução Conjunta SEMAD/FEAM/IEF/IGAM no 2.466, de 13 de fevereiro de 2017. Institui a Infraestrutura de Dados Espaciais do Sistema Estadual de Meio Ambiente e Recursos Hídricos e cria seu Comitê Gestor. Disponível em: <http://www.agencia.baciaspcj.org.br/docs/resolucoes/resolucao-semad-feam-ief-igam2466-17.pdf>. Acesso em: 10 out. 2019.

Minas Gerais. Resolução Conjunta SEMAD/FEAM/IEF/IGAM no 2.631, de 02 de maio de 2018. Altera a Resolução Conjunta Semad/Feam/IEF/Igam no 2.466, de 13 de fevereiro de 2017, que institui a Infraestrutura de Dados Espaciais do Sistema Estadual de Meio Ambiente e Recursos Hídricos e cria seu Comitê Gestor. Disponível em: $<$ http://www.siam.mg.gov.br/sla/download.pdf?idNorma=46118>. Acesso em: 10 out. 2019.

Santos, A. F. Estudo agroambiental de uma microbacia hidrográfica, visando sua sustentabilidade. Botucatu: Universidade Estadual Paulista "Júlio de Mesquita Filho", 2009. (Tese de doutorado).

Shigunov Neto, A.; Campos, L. M. S.; Shigunov, T. Fundamentos da gestão ambiental. Rio de Janeiro: Ciência Moderna, 2009.

Silva, J. A. A.; Nobre, A. D.; Manzatto, C. V.; Joly, C. A.; Rodrigues, R. R.; Skorupa, L. A.; Nobre, C. A.; Ahrens, S.; May, P. H.; Sá, T. D. A.; Cunha, M. C.; Rech Filho, E. L. 0 Código Florestal e a Ciência: contribuições para o diálogo. São Paulo: Sociedade Brasileira para o Progresso para o diálogo, SBPC; Academia Brasileira de Ciências, ABC, 2011. Disponível em: <http://www.abc.org.br/IMG/pdf/doc-547.pdf>. Acesso em: 19 out. 2019.

Vaeza, R. F.; Filho Oliveira, P. C.; Maia, A. G.; Disperati, A. A. Uso e ocupação do solo em bacia hidrográfica urbana a partir de imagens orbitais de alta resolução. Floresta e Ambiente, v. 17, p. 23-29. 2010. https://doi.org/10.4322/floram.2011.003

Viana, V. M.; Pinheiro, L. A. F. V. Conservação da biodiversidade em fragmentos florestais. Série Técnica IPEF, v. 12, p. 25-42, 1998. Disponível em: <http://www.ipef.br/publicacoes/stecnica/nr32/cap03.pdf>. Acesso em: 09 set. 2019. 